\title{
ASOSIASI FUNGI MIKORIZA ARBUSKULA (FMA) PADA RHIZOPHORA spp DI DESA TERUSAN KECAMATAN MEMPAWAH HILIR KALIMANTAN BARAT
}

\author{
(Association of Arbuscular Mycorrhizal Fungi (FMA) on the Rhizophora spp In The Terusan \\ Village Mempawah Hilir Districts West Kalimantan)
}

\author{
Abdul Samad, Burhanuddin, dan Iskandar AM \\ Fakultas Kehutanan, Universitan Tanjungpura Jl. Prof. Hadari Nawawi, Pontianak. 78121 \\ Email : abdul_samad08@yahoo.com
}

\begin{abstract}
Symbiosis of Arbuscular Mycorrhizal Fungi (AMF) with Rhizophora spp was observed a Terusan Village, Mempawah Hilir Districts, West Kalimantan.. Purpose of the study is : (1) want to obtain information of association of AMF with Rhizophora spp , (2) the types of AMF associated with Rhizophora spp. This research was conducted for 3 months in Terusan Village, Mempawah Hilir District, West Kalimantan and Silviculture Laboratory, Faculty of Forestry, Tanjungpura University. The research was conducted by lane technique survey method. The results of this study showed that there are 7 types of AMF namely Gigaspora sp, Glomus sp1, Glomus sp2, Glomus sp3, Glomus sp4, Glomus sp5, and Glomus sp6. The total number of spores there are 2,903 spores while for the root sample found the internal hyphae and vesicle in the root.
\end{abstract}

Keywords: Rhizophora spp, mycorrhiza, Mangrove, Terusan Village

\section{PENDAHULUAN}

Hutan mangrove merupakan suatu ekosistem yang mempunyai peranan penting ditinjau dari sisi ekologis maupun aspek sosial ekonomi. Hutan mangrove mempunyai fungsi ganda dan mata rantai yang sangat penting dalam memelihara keseimbangan siklus biologi di perairan (Waas dan Nabaan, 2010). Hutan mangrove juga merupakan tipe hutan yang ditumbuhi dengan hutan bakau (mangrove) yang khas yang terdapat di sepanjang pantai dan muara sungai yang di pengaruhi oleh pasang surut air laut (Onrizal, 2010). Hutan mangrove umumnya terdapat di seluruh pantai Indonesia dan hidup serta tumbuh berkembang pada lokasi yang mempunyai hubungan pengaruh pasang air (pasang surut) yang berembes pada aliran sungai yang terdapat di sepanjang pesisir pantai.

Ekosistem mangrove dapat tumbuh dengan baik pada zona pasang-surut di sepanjang garis pantai daerah tropis seperti laguna, rawa, delta, dan muara sungai. Ekosistem mangrove bersifat komplek dan dinamis tetapi labil. Komplek, karena di dalam ekosistem mangrove dan perairan maupun tanah di bawahnya merupakan habitat berbagai jenis satwa daratan dan biota perairan. Dinamis, karena ekosistem mangrove dapat terus tumbuh dan berkembang serta mengalami suksesi serta perubahan zonasi sesuai dengan tempat tumbuh. Labil, karena mudah sekali rusak dan sulit untuk pulih kembali (Gunawan dan Anwar, 2006 dalam Haris risma, 2014). 
Mikroba-mikroba tanah banyak yang berperan di dalam penyediaan maupun penyerapan unsur hara bagi tanaman. Tiga unsur hara penting tanaman, yaitu nitrogen $(\mathrm{N})$, fosfat (P), dan kalium (K), seluruhya melibatkan aktivitas mikroba tanah. Hara $\mathrm{N}$ sebenarnya tersedia melimpah di udara. Kurang lebih $74 \%$ kandungan udara adalah N. Namun, N udara tidak dapat langsung diserap oleh tanaman. Tidak ada satupun tanaman yang dapat menyerap $\mathrm{N}$ langsung dari udara. $\mathrm{N}$ harus difiksasi/ditambat oleh mikroba tanah dan diubah bentuknya menjadi tersedia bagi tanaman. Mikroba penambat $\mathrm{N}$ ada yang bersimbiosis dengan tanaman dan ada pula yang hidup bebas di sekitar perakaran tanaman. Mikroba penambat $\mathrm{N}$ simbiotik antara lain: Rhizobium sp. Rhizobium sp hidup di dalam bintil akar tanaman kacang-kacangan (leguminose). Mikoroba penambat $\mathrm{N}$ non-simbiotik misalnya: Azospirillum sp dan Azotobacter sp. Mikroba penambat $\mathrm{N}$ simbiotik hanya bisa digunakan untuk tanaman leguminose saja, sedangkan mikroba penambat $\mathrm{N}$ nonsimbiotik dapat digunakan untuk semua jenis tanaman. Mikroba tanah lain yang berperan di dalam penyediaan unsur hara tanaman adalah mikroba pelarut fospat $(\mathrm{P})$ dan kalium (K).

Beberapa jenis pohon yang terbukti berasosiasi dengan mikoriza adalah Avicennia spp (Gustian. 2015), Xylocarpus Granatum dan Bruguiera Gymnorzha (Hamzah et al, 2012), Acacia crassicarpa (setiadi. 1998), Ramin (Muin. 2003), Jelutung (Turjaman. 2007), Jelutung dan Prepat (Burhanuddin. 2011), Ketapang (Petrus et al, 2013), dan Laban (Sandi et al, 2013). Permasalahannya sampai sekarang belum diketahui adanya hubungan/asosiasi antar FMA dengan jenis Rhizophora Spp pada hutan mangrove dan jenis-jenis FMA yang berasosiasi dengan jenis-jenis Rhizophora spp pada hutan mangrove.

Tujuan penelitian adalah: (1) ingin memperoleh informasi asosiasi FMA dengan Rhizophora spp, (2) jenis-jenis FMA yang berasosiasi dengan Rhizophora spp. Hasil penelitian diharapkan dapat di jadikan sebagai informasi awal penelitian dan pengembangan lebih lanjut dan pemanfaatan FMA untuk meningkatkan pertumbuhan Rhizophora spp pada daerah pesisir dengan pemanfaatan FMA sebagai agen hayati.

\section{METODE PENELITIAN}

Penelitian ini dilaksanakan selama 3 bulan di Desa Terusan Kecamatan Mempawah Hilir Kabupaten Mempawah Provinsi Kalimatan Barat dan di Lab Silvikultur Fakultas Kehutanan Universitas Tanjungpura. Pengambilan sampel tanah dan akar di Desa Terusan dengan teknik jalur. Jalur pengamatan ada 4. Setiap jalur di ambil 2 titik pengambilan sampel yaitu dengan jarak $15 \mathrm{~m}$ dan $30 \mathrm{~m}$ dari tepi sungai dan jarak antar jalur $15 \mathrm{~m}$, sedangkan untuk 1 titik pengambilan sampel tanah dan akar dilakukan 3 kali ulangan pada beberapa titik disekitar perakaran tanaman dengan kedalaman 10 cm. Sampel-sampel tanah dianalisis di laboratorium untuk pengujian adanya asosiasi antara Rhizophora spp dan mikoriza.

\section{HASIL DAN PEMBAHASAN}

Hasil isolasi dan identifikasi tipe spora FMA dari tanah di tegakan bakau Desa Terusan, yang di dasarkan pada 
perbedaan bentuk spora, warna spora, permukaan spora dan lekatan tangkai hifa di temukan 2 genus yaitu genus Gigaspora dan Glomus. Total tipe spora FMA 7 jenis, genus yang terbanyak ditemukan yaitu genus Glomus dengan 6 jenis.

Tabel 1. Kerapatan Spora FMA dari Masing-masing Contoh Tanah (Density of Arbuscular Mycorrhizal Fungi (AMF) Spore of Each Soil Sample).

\begin{tabular}{|c|c|c|c|c|c|c|c|c|c|c|c|}
\hline \multirow{4}{*}{$\begin{array}{l}\text { Jenis } \\
\text { FMA }\end{array}$} & \multirow{2}{*}{\multicolumn{8}{|c|}{$\begin{array}{c}\text { Jumlah Spora FMA/100 gr Sampel Tanah } \\
\text { Jalur }\end{array}$}} & \multirow{4}{*}{ Populasi } & \multirow{4}{*}{ Rerata } & \multirow{4}{*}{ Frekuensi } \\
\hline & & & & & & & & & & & \\
\hline & \multicolumn{2}{|c|}{1} & \multicolumn{2}{|c|}{2} & \multicolumn{2}{|c|}{3} & \multicolumn{2}{|c|}{4} & & & \\
\hline & 15 & 30 & 15 & 30 & 15 & 30 & 15 & 30 & & & \\
\hline $\mathrm{pH}$ & 6,9 & 7,0 & 7,0 & 7,0 & 7,0 & 6,8 & 7,0 & 7,0 & & & \\
\hline Gigaspora sp & 219 & 192 & 124 & 125 & 115 & 112 & 87 & 100 & 1.074 & 134,5 & 0,37 \\
\hline Glomus sp1 & 13 & 23 & 17 & 20 & 30 & 31 & 20 & 19 & 173 & 21,6 & 0,06 \\
\hline Glomus sp2 & 62 & 31 & 39 & 42 & 49 & 42 & 40 & 30 & 345 & 43,1 & 0,12 \\
\hline Glomus sp3 & 29 & 55 & 39 & 42 & 38 & 36 & 29 & 25 & 293 & 36,6 & 0,10 \\
\hline Glomus sp4 & 23 & 105 & 73 & 50 & 51 & 40 & 42 & 28 & 412 & 51,5 & 0,14 \\
\hline Glomus sp5 & 16 & 28 & 27 & 29 & 51 & 49 & 42 & 37 & 279 & 34,9 & 0,10 \\
\hline Glomus sp6 & 21 & 36 & 30 & 41 & 61 & 54 & 52 & 42 & 327 & 40,9 & 0,11 \\
\hline Kerapatan spora & 383 & 470 & 349 & 349 & 395 & 364 & 312 & 281 & 2.903 & 362,9 & 1,00 \\
\hline Jumlah Jenis & 7 & 7 & 7 & 7 & 7 & 7 & 7 & 7 & & & \\
\hline
\end{tabular}

Berdasarkan Tabel 1, dapat di jelaskan bahwa kerapatan spora antara 281 - 470 spora /100 gr tanah, dengan jumlah spora keseluruhan 2.903 spora dengan rerata 362,9. Kerapatan spora terendah terdapat pada jalur 4 pada jarak 30 meter dari tepi sungai ada sejumlah 281 spora sedangkan kerapatan tertinggi spora terdapat pada jalur 1 dengan jarak 30 meter dari tepi sungai ada sejumlah 470 spora, mempunyai kesamaan pada kerapatan spora yaitu pada jalur 2 dengan jarak 15 meter dan 30 meter dengan jumlah spora 349. Hal ini menunjukan tiap contoh tanah masing-masing jarak dari tepi sungai mempunyai kerapatan spora FMA dengan variasi yang tinggi, sedangkan untuk jumlah jenis spora antara jenis spora setiap jalurnya, jumlah jenis spora rendah terdapat pada 15 meter dari tepi sungai dengan jumlah jenis spora 13 spora dan jumlah jenis spora yang tinggi terdapat pada 15 meter dari tepi sungai dengan jumlah spora 291 spora. Karakterisasi yang dapat dilihat dari bentuk spora yaitu warna spora, permukaan spora dan lekatan tangkai hifa, dapat dilihat pada Tabel 2. 
JURNAL TENGKAWANG (2017)

Vol. 7 (1) : 11 - 18

Tabel 2. Tipe dan Karakteristik Morfotipe spora Fungi Mikoriza Arbuskula (FMA) dengan perbesaran $400 \times$ (Types and Characteristics Morphotipe spore Arbuscular Mycorriza Fungi (AMF) with magnification 400 X)

\begin{tabular}{|c|c|}
\hline Tipe Spora & Karakteristik Spora \\
\hline 1 & 2 \\
\hline 1. Gigaspora $\mathrm{sp}$ & $\begin{array}{l}\text { Spora berbentuk bulat, warna spora coklat keputihan, } \\
\text { permukaan spora kasar, terdapat perlekatan hifa, spora lolos } \\
\text { pada saringan } 0,21 \mathrm{~mm} \text {. }\end{array}$ \\
\hline 2. Glomus sp1 & $\begin{array}{l}\text { Spora berbentuk bulat, warna spora coklat kemerahan, } \\
\text { permukaan spora, permukaan spora kasar, terdapat } \\
\text { perlekatan hifa, spora lolos pada saringan } 125 \mu \mathrm{m} \text {. }\end{array}$ \\
\hline 3. Glomus sp2 & $\begin{array}{l}\text { Spora berbentuk bulat, warna spora coklat kemerahan, } \\
\text { permukaaan spora halus, tidak terdapat perlekatan hifa, } \\
\text { spora lolos pada saringan } 0,21 \mathrm{~mm}\end{array}$ \\
\hline & $\begin{array}{l}\text { Spora berbentuk lonjong, warna spora coklat keputihan, } \\
\text { permukaan spora halus, terdapat perlekatan hifa, spora lolos } \\
\text { pada saringan } 0,21 \mathrm{~mm} \text {. }\end{array}$ \\
\hline 5. Glomus sp4 & $\begin{array}{l}\text { Spora berbentuk bulat, warna spora coklat kehitaman, } \\
\text { permukaan spora kasar, terdapat perlekatan hifa, spora lolos } \\
\text { pada saringan } 0,21 \mathrm{~mm}\end{array}$ \\
\hline 6. Glomus sp5 & $\begin{array}{l}\text { Spora berbentuk lonjong, warna spora coklat kemerahan, } \\
\text { permukaan spora kasar, terdapat perlekatan hifa, spora lolos } \\
\text { pada saringan } 0,21 \mathrm{~mm}\end{array}$ \\
\hline 7. Glomus sp6 & $\begin{array}{l}\text { Spora berbentuk bulat, warna spora coklat keputihan, } \\
\text { permukaan spora halus, tidak terdapat perlekatan hifa, spora } \\
\text { lolos pada saringan } 0,21 \mathrm{~mm}\end{array}$ \\
\hline
\end{tabular}


Persentasi akar terinfeksi di tentukan berdasarkan berapa banyaknya hifa FMA yang terinfeksi akar atau juga ada tidaknya spora yang terdapat dalam lapisan akar (kortek), sehingga apabila terdapat hifa atau spora FMA yang menginfeksi akar maka akan didapatkan tingkat presentasi infeksi akar baik itu sangat tinggi, tinggi, sedang, rendah maupun sangat rendah. Untuk tingkat presentasi akar pada Rhizophora spp dapat dilihat pada Tabel 3.

Tabel 3. Infeksi Fungi Mikoriza Arbuskula (FMA) pada akar Rhizophora spp (Infection of Arbuscular Mycorrhizal Fungi (AMF) on Roots of Rhizophora spp).

\begin{tabular}{|c|c|c|c|c|c|c|}
\hline Jalur/Titik & $\begin{array}{l}\text { Tinggi } \\
\text { Pohon } \\
(\mathrm{m})\end{array}$ & $\begin{array}{l}\text { Diamater } \\
\text { Pohon } \\
(\mathrm{cm})\end{array}$ & $\begin{array}{c}\text { Jumlah } \\
\text { Potongan } \\
\text { Akar (x) }\end{array}$ & $\begin{array}{c}\text { Jumlah } \\
\text { Akar } \\
\text { Terinfeksi }\end{array}$ & $\begin{array}{c}\text { \% Infeksi } \\
\text { Jumlah } \\
\text { Keseluruhan } \\
\text { Akar } \\
\end{array}$ & Keterangan \\
\hline \multicolumn{7}{|l|}{ Jalur 1} \\
\hline 15 meter & 3,0 & 10,0 & 10 & 6 & 60 & Tinggi \\
\hline 30 meter & 3,5 & 9,0 & 10 & 4 & 40 & Sedang \\
\hline Rata-rata & 3,25 & 9,5 & 10 & & & \\
\hline \multicolumn{7}{|l|}{ Jalur 2} \\
\hline 15 meter & 3,0 & 9,0 & 10 & 5 & 50 & Sedang \\
\hline 30 meter & 4,5 & 15,0 & 10 & 4 & 40 & Sedang \\
\hline Rata-rata & 3,75 & 12,0 & 10 & & & \\
\hline \multicolumn{7}{|l|}{ Jalur 3} \\
\hline 15 meter & 2,3 & 8,5 & 10 & 4 & 40 & Sedang \\
\hline 30 meter & 4,0 & 13,0 & 10 & 3 & 30 & Sedang \\
\hline Rata-rata & 3,15 & 10,75 & 10 & & & \\
\hline \multicolumn{7}{|l|}{ Jalur 4} \\
\hline 15 meter & 2,6 & 8,0 & 10 & 4 & 40 & Sedang \\
\hline 30 meter & 3,0 & 8,0 & 10 & 4 & 40 & Sedang \\
\hline Rata-rata & 2,8 & 8,0 & 10 & & & \\
\hline
\end{tabular}

Hasil penelitian mengenai akar yang terinfeksi berkisar antara 30-60\%. Infeksi akar $30 \%$ terdapat pada titik sampel J3. 30 meter, infeksi akar 40\% terdapat pada titik sampel J1. 30 meter, J2. $30 \quad$ meter,
J3. 15 meter J4. 15 meter dan J4. 30 meter, infeksi akar $50 \%$ terdapat pada titik sampel J2. 15 meter sedangkan infeksi akar $60 \%$ terdapat pada titik sampel J1. 15 meter dari tepi sungai. 
JURNAL TENGKAWANG (2017)

Vol. 7 (1) : 11 - 18

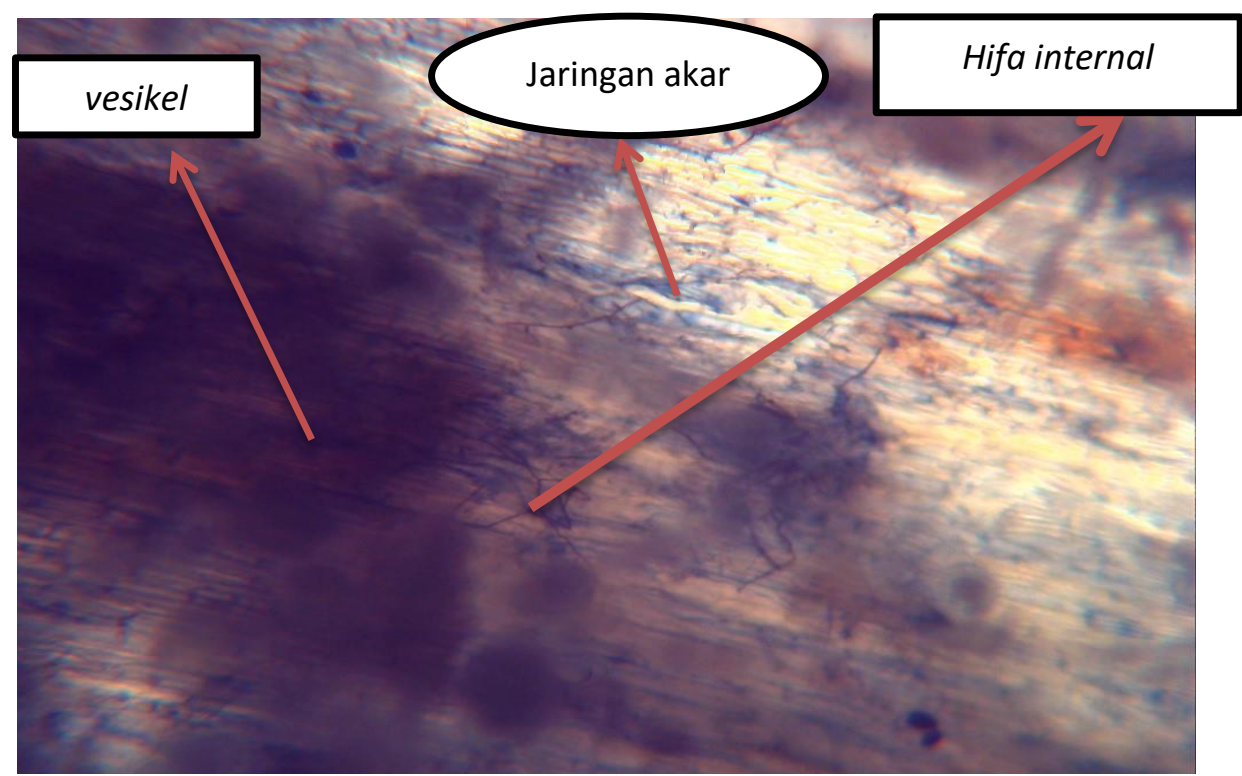

Gambar 1. Infeksi akar pada tanaman Rhizophora spp (Root infection in Rhizophora spp)

Berdasarkan hasil penelitian menunjukan bahwa pada daerah tepi sungai di Desa Terusan Kecamatan Mempawah Hilir Kabupaten Mempawah, di temukan mikoriza arbuskula (FMA) yang berasosiasi dengan tanaman Rhizophora spp. Keberadaan fungi mikoriza arbuskula (FMA) tersebut sesuai dengan Nurhamara (1994) bahwa mikoriza memperlihatkan asosiasi yang sangat luas. Secara geografis asosiasi tersebut menyebar dari daerah bergurun pasir hinga hutan hujan, secara global fungi mikoriza arbuskula (FMA) dapat di jumpai universal bagi ekosistem tumbuhan.

Adanya struktur infeksi fungi mikoriza arbuskula (FMA) pada gambar 1 berupa hifa internal dalam sel jaringan akar. Struktur infeksi tersebut mencirikan dianogstik adanya infeksi fungi mikoriza arbuskula (FMA) dalam akar. Hasil penelitian ini penunjang asumsi bahwa tanaman Rhizophora spp yang di ambil sebagai sampel merupakan inang dari FMA yang pertumbuhannya juga di pengaruhi oleh aktivitas FMA yang berasosiasi dengan tanaman Rhizophora spp.

Keberadaan FMA dibuktikan dengan adanya jenis-jenis spora hasil isolasi yang ditemukan pada sampel tanah yang diamati dan adanya struktur infeksi FMA. Kondisi dalam sel-sel akar pada 8 sampel tanaman Rhizophora spp menunjukan adanya FMA yang dapat berasosiasi dengan inang tanaman Rhizophora spp.

\section{Kesimpulan}

Dari hasil penelitian yang telah dilakukan maka dapat disimpulkan bahwa: adanya hubungan asosiasi antara FMA dengan tegakan Rhizophora spp. Hal ini ditunjukan dengan adanya spora FMA dan struktur infeksi FMA (hifa internal) pada tegakan Rhizophora spp dan hasil isolasi spora FMA pada 
tegakan Rhizophora spp di temukan 2.903 spora/100 gram tanah. Berdasarkan hasil karakteristik tipe spora ditemukan tujuh jenis spora dari dua genus, yaitu genus Gigaspora dan Glomus.

\section{Saran}

Untuk penanaman jenis Rhizophora spp di Desa Terusan dengan memanfaatkan Fungi Mikoriza Arbuskula (FMA) dari genus Gigaspora dan Glomus. Perlu dilakukan penelitian lebih lanjut untuk mengetahui efektifitas asosiasi yang terjadi (uji efektivitas) dan uji tingat ketergantungan Rhizophora spp terhadap FMA di Desa Terusan Kecamatan Mempawah Hilir Kabupaten Mempawah Provinsi Kalimantan Barat.

\section{DAFTAR PUSTAKA}

Angga, Tri Rima Setyawati, Ari Pewi yanti. 2015. Keragaman Jenis Burung Air di Kawasan Hutan Mangrove Primer dan Hutan Mangrove Hasil Reboisasi Di Kabupaten Mempawah. Jurnal Protobiont. FMIPA UNTAN. Pontianak.

Burhanuddin. 2011. Asosiasi Jamur Mikoriza Arbuskula Dengan Preparat (Combretocarpus rotundatus Miq) Dan Jelutung (Dyera lowii Hook) Di Lahan Gambut [disertasi]. Yogyakarta: Program Pascasarjana, Universitas Gadjah Mada

Brundrett M, Bougher N, Dell B, Grove T, Malajczuk N. 1996. Working with mychorrhizas in forestry and agriculture. (ACIAR). http:// www.ffp.csiro.au/research/mycorr hiza/index.html, di akses 26 Januari 2017
Gustian, Burhanuddin dan Ratna Herawatiningsih. 2015. Asosiasi Fungi Mikoriza Arbuskula (FMA) Pada Avicenia Spp di Desa Terusan Kecamatan Mempawah Hilir Kalimantan Barat. Jurnal Hutan Lestari. Fakultas Kehutanan. Universitas Tanjungpura. Pontianak.

Hamzah, Nursanti dan Rike Puspitasari. 2012. Identifikasi Fungsi Mikoriza Arbuskular (Fma) Di Hutan Lindung Mangrove Pangkal Babu Kabupaten Tanjung Jabung Barat Jambi. Jurnal Fakultas Pertanian Universitas Jambi. Jambi

Haris Risma. 2014. Keanekaragaman Vegetasi dan Satwa Liar Hutan Mangrove. Jurnal Bionature. Makassar.

Muin. A. 2003. Penanaman Ramin (Gonystylus bancanus Miq.Kurz) Pada Areal Bekas Tebangan Dengan Inokulasi CMA Dan Pemupukan Fosfat Alam Terhadap Bibit Di Persemaian. Laporan Hasil Penelitian hibah bersaing XI. Lemlit. (Tidak dipublikasi).

Onrizal. 2010. Perubahan Tutupan Hutan Mangrove di Pantai Timur Sumatera Utara Periode 1977 2006. Jurnal Biologi Indonesia. Bogor: DIPA Puslit Biologi-LIPI Bogor (2): hlm 163-170.

Petrus, Burhanuddin, dan Wulandari RS. 2013. Asosiasi Cendawan mikoriza Arbuskula (CMA) Pada Ketapang(Terminalia Catappa). Jur Hutan Lestari. Pontianak. Universitas Tanjungpura Pontianak.

Setiadi Y. 1998. Peranan Mikoriza dalam Kehutanan. Departemen 
Pendidikan dan Kebudayaan, Dirjen Pendidikan Tinggi PAU Bioteknologi. IPB Bogor

Turjaman M, Saito H, Santoso E, Susanto A, Sampang G, Limin SH, Shibuya M, Tahahashi K, Tamai Y, Osaki M, Tawaraya K. 2007. Effect Of Ektomiccorizal Fungi Inoculeted In Shorea Balaigeran Under Field Condition In Peat-Swamp Forest. Dalam Processing International
Symposopmand Workshop On Tropical Peatlend. CarbonClimete-Human InteractionCarbon Pools, Fire, Intigation Resroration And Wise Use. Yogyakarta. Indonesia.

Waas J.B.D., dan Nabaan B. 2010. Pemetaan dan Analisis Index Vegetasi Mangrove Di Pulau Saparua Maluku Tengah. Jurnal Ilmu Aeknologi Kelautan Tropis. 